\title{
A U5 Small Nuclear Ribonucleoprotein Particle Protein Involved Only in the Second Step of Pre-mRNA Splicing in Saccharomyces cerevisiae
}

\author{
DAVID S. HOROWITZ $\dagger$ AND JOHN ABELSON* \\ Division of Biology 147-75, California Institute of Technology, Pasadena, California 91125
}

Received 25 November 1992/Returned for modification 4 January 1993/Accepted 3 February 1993

\begin{abstract}
The PRP18 gene, which had been identified in a screen for pre-mRNA splicing mutants in Saccharomyces cerevisiae, has been cloned and sequenced. Yeast strains bearing only a disrupted copy of PRP18 are temperature sensitive for growth; even at a low temperature, they grow extremely slowly and do not splice pre-mRNA efficiently. This unusual temperature sensitivity can be reproduced in vitro; extracts immunodepleted of PRP18 are temperature sensitive for the second step of splicing. The PRP18 protein has been overexpressed in active form in Escherichia coli and has been purified to near homogeneity. Antibodies directed against PRP18 precipitate the U4/U5/U6 small nuclear ribonucleoprotein particle (snRNP) from yeast extracts. From extracts depleted of the U6 small nuclear RNA (snRNA), the U4 and U5 snRNAs can be immunoprecipitated, while no snRNAs can be precipitated from extracts depleted of the U5 snRNA. PRP18 therefore appears to be primarily associated with the U5 snRNP. The antibodies against PRP18 inhibit the second step of pre-mRNA splicing in vitro. Together, these results imply that the US snRNP plays a role in the second step of splicing and suggest a model for the action of PRP18.
\end{abstract}

The splicing of pre-mRNA takes place in two sequential cleavage-and-ligation reactions (reviewed in references 26, 27 , and 59). In the first step, the pre-mRNA is cut at the $5^{\prime}$ splice site, releasing the first exon; concomitantly, the 5' phosphoryl group at the end of the intron is ligated to the 2' hydroxyl of an internal adenosine, yielding a branched RNA termed a lariat. In the second step, cleavage at the $3^{\prime}$ splice site is accompanied by ligation of the two exons, yielding the product mRNA and releasing the intron as a lariat. Each cleavage and ligation step is thought to be a concerted, transesterification reaction in which the number of phosphodiester bonds is conserved. The identical reactions occur during group II self-splicing, leading to the hypothesis that RNA is also the catalyst in pre-mRNA splicing (36). The splicing of pre-mRNA occurs on a large ribonucleoprotein particle (RNP) called the spliceosome $(13,24)$, which consists of five small nuclear RNAs (snRNAs), U1, U2, U4, U5, and U6, and a large but undetermined number of proteins $(17,25,39,53)$.

pre-mRNA splicing occurs in all eukaryotes, and its mechanism appears to be conserved from yeasts to metazoans. Although much has been learned about the functions of the snRNAs and the splicing proteins, a complete accounting of the role of any of the splicing factors cannot presently be given. Each snRNA is part of a small nuclear RNP (snRNP) (reviewed in reference 44). The U1 and U2 snRNPs are involved in recognition of splice sites; U1 base pairs to the $5^{\prime}$ splice site, and U2 base pairs to the branchpoint sequence (see reference 57 and previously cited reviews). The U4 snRNA base pairs to the U6 snRNA, and together they form a single snRNP $(12,29)$. The U5 snRNP binds to the U4/U6 snRNP, forming a stable complex $(9,17,39)$. It is in this complex that U4, U5, and U6 enter the spliceosome $(41,61)$, but they do not remain associated throughout the splicing

\footnotetext{
* Corresponding author.

$\dagger$ Present address: Cold Spring Harbor Laboratory, Cold Spring Harbor, NY 11724.
}

reaction. U4 is apparently needed only for assembly of the spliceosome, and it leaves the spliceosome before the first cleavage reaction (76). U6 appears to be involved in both steps of splicing (20), and a catalytic role for the U6 snRNA in the splicing reaction has been proposed $(14,20,67)$. The role of the U5 snRNP has been difficult to uncover. It is a large particle, apparently containing more proteins than the other snRNPs (4). Recent genetic evidence suggests a role for the U5 snRNP in the recognition of both the $5^{\prime}$ and $3^{\prime}$ splice sites $(48,49)$.

A variety of proteins are required for splicing. They include proteins involved in recognition and selection of the $5^{\prime}$ and $3^{\prime}$ splice sites and of the branchpoint sequence (see cited reviews). Several proteins, known from genetic studies in Saccharomyces cerevisiae, appear to be RNA-dependent ATPases whose roles in splicing may be to alter the conformations of the snRNAs or the pre-mRNA or to ensure the fidelity of splicing (reviewed in reference 60). These ATPases are needed during the assembly of the spliceosome, during both steps of splicing, and for the release of the mRNA. Many proteins associated with snRNPs are known (reviewed in reference 44). For the most part, their functions are unknown, although they are clearly involved in the nuclear transport of snRNPs, in maintaining the structures of individual snRNPs, and in the interactions between snRNPs. Two of the best-studied snRNP proteins are the yeast PRP4 and PRP8 proteins. PRP4, a component of the U4 snRNP, is involved in the binding of U4/U6 to U5 $(7,11,52,75)$; PRP8 is part of the U5 snRNP and appears to contact the premRNA during splicing $(35,43,72)$.

In $S$. cerevisiae, screening of temperature-sensitive mutants for splicing defects has been the principal method for identifying splicing factors $(46,56,71)$. Such screens have yielded about 20 genes, known as $P R P$ (for pre-mRNA processing) genes, required for splicing. The PRP18 gene, found by Vijayraghavan et al. (71), was of particular interest because of its involvement in the second step of splicing. Both in vivo and in vitro, the second step of splicing was 
found to be inhibited when PRP18 was defective $(70,71)$. At the restrictive temperature, splicing in most of the temperature-sensitive prp mutants is blocked at the first step, often as a result of failure of the spliceosome to assemble. In contrast, the involvement of PRP18 in the second step of splicing suggested that PRP18 might directly affect the formation of covalent bonds in splicing and that study of it could yield insights into the mechanisms of catalysis in splicing. We report here the sequencing of the PRP18 gene, the analysis of a null allele of $P R P 18$, and the production of active PRP18 protein. We find that PRP18 is a part of the U5 snRNP, implying a role for this snRNP in the second step of splicing.

\section{MATERIALS AND METHODS}

Materials and strains. Plasmids were prepared from Escherichia coli JM101. PRP18 was purified from $E$. coli BL21(DE3) (65) transformed with pDH111. Yeast strains SS330 and SS328 and the temperature-sensitive prp18 strain 503-6c are described in reference 71; strains EJ101 ( $\alpha$ his 1 prb1-1122 prc1-126) and CBO18 (a CRY1 pep44::HIS3 prb1::hisG prc1 $1:$ :hisG) (from J. Robinson, California Institute of Technology) were used for making wild-type extracts. A haploid strain (a ura3-52 trp1-289 his3-532 lys2-801 ade2-101 snr7::TRP1) transformed with plasmid pBWHisG7 was used for making the U5-depleted extract (50). Restriction enzymes and DNA- and RNA-modifying enzymes were from New England Biolabs, Boehringer Mannheim Biochemicals, and Bethesda Research Laboratories. Sequenase and sequencing reagents were from U.S. Biochemical. $\left[\alpha^{-32} \mathrm{P}\right] \mathrm{dATP},\left[\gamma^{-32} \mathrm{P}\right] \mathrm{ATP}$, and GeneScreen were from NEN; $\left[\alpha-{ }^{32}\right.$ P]UTP and the ECL Western immunoblotting detection system were from Amersham. The Enzygraphic Web was from International Biotechnologies, Inc. DE52 and CM52 were purchased from Whatman. Red Sepharose and protein A-Sepharose were bought from Pharmacia. Nitrocellulose and tresyl-activated agarose were from Schleicher \& Schuell. Leupeptin and aprotinin were from Boehringer Mannheim Biochemicals. Phenylmethylsulfonyl fluoride, benzamidine, pepstatin A, and S Sepharose were from Sigma. Polyethyleneimine was from Miles Laboratories. RNA molecular weight markers were from Bethesda Research Laboratories. The PRP4 antibody ( $\alpha$ PRP4) was obtained from J. Banroques and is described in reference 7. Antibodies to PRP18 were prepared by Cocalico Biologicals, Inc., Reamstown, Pa.

Sequencing. The 2.5-kb BamHI-NruI fragment from pUV18 (70) was cloned in the SmaI site of Bluescript KS+ and KS-, giving PRP18KS + and PRP18KS - . Nested deletions were made, and single-stranded DNAs were sequenced with Sequenase according to the manufacturer's directions. Both strands were sequenced. Sequence analysis was carried out with GCG (18); homology searches were done with FASTA, TFASTA (51), and BLAST (2).

Complementation. Four plasmids, pDH101 to 104, were made by cloning the $2.5-\mathrm{kb}$ BamHI-EcoRI, the 1.9-kb HindIII-EcoRI, the 1.2-kb BamHI-SphI, or the 1.1-kb BamHIEcoRV fragment (Fig. 1B) into the polylinker of the yeast shuttle vector pPHYC18 (30), which contains the URA3 gene. The temperature-sensitive prp18 strain 503-6c (70) was transformed (34) with pDH101 to 104, plated and restreaked on selective medium (eight transformants for each plasmid), and tested for growth at $37^{\circ} \mathrm{C}$. Only 503-6c transformed with pDH102 (HindIII-EcoRI) did not grow at $37^{\circ} \mathrm{C}$.

Disruptions. Two plasmids, pDH120 and pDH121, were made from PRP18KS + by replacing the MscI-HindIII fragment (within PRP18) or the SphI-MluI fragment (within MUQ1) with the 1.8-kb BamHI-BamHI fragment containing the HIS3 gene (64) (from C. O'Day, California Institute of Technology). In pDH120 and pDH121, HIS3 is transcribed in the same direction as $P R P 18$. In two additional, analogous plasmids, pDH120R and pDH121R, the orientation of the HIS3 fragment was reversed. The four plasmids were cut with EcoRI and $\mathrm{XbaI}$ and were transformed into SS330 $\times$ SS328 (31), yielding the yeast strains DH120, DH120R, DH121, and DH121R. Disruptions were verified by Southern blotting. Tetrads were dissected, and markers and mating types were checked. DH120 and DH120R were transformed with pDH101, pDH104, and pUV18 (70), and tetrads were again dissected and analyzed. Results were as follows. Only half of the spores (from 15 tetrads, 23 of 60 spores survived) from DH120 were viable, and all of the viable spores were His $^{-}$, suggesting that $P R P 18$ is essential. However, the inviable spores could be rescued only by pUV18, a 7-kb clone which includes $3 \mathrm{~kb}$ upstream of PRP18 (from nine tetrads, 26 of 36 spores survived, and all 12 viable $\mathrm{His}^{+}$ spores were $\mathrm{Ura}^{+}$). Viability of $\mathrm{His}^{+}$spores was not restored by pDH101 (from 11 tetrads, 16 of 16 spores retaining the plasmid were $\mathrm{His}^{-}$) or pDH104 (from 10 tetrads, 6 of 6 spores retaining the plasmid were $\mathrm{His}^{-}$). Hence, the lethality of this disruption was most likely due to its effect on a gene upstream of $P R P 18$. Transcript B in Fig. 2 is presumably the transcript of this gene. All spores from DH120R were viable (from 17 tetrads, 47 of 68 spores survived). The two $\mathrm{His}^{+}$ spores from each tetrad grew very slowly at 23 and $30^{\circ} \mathrm{C}$ (doubling time of $6 \mathrm{~h}$ at $23^{\circ} \mathrm{C}$ ) and did not grow at $37^{\circ} \mathrm{C}$. The temperature-sensitive defect could be remedied by any plasmid bearing the PRP18 gene. (Each of the three plasmids was transformed into two independent $\mathrm{His}^{+}$, temperaturesensitive clones; four transformants of each clone were analyzed.) Spore viability from the dissections of DH121 and DH121R was low ( 9 of 28 viable spores from DH121 and 18 of 40 viable spores from DH121R); however, $\mathrm{His}^{+}$and $\mathrm{His}^{-}$ spores survived in roughly equal numbers, implying that MUQ1 is not essential. $\mathrm{His}^{+}$spores from DH121R gave small colonies, which were temperature sensitive, possibly because of interference with expression of PRP18.

Transcription. Poly $(\mathrm{A})^{+}$RNA was made from $S$. cerevisiae EJ101 by standard methods (63) and was analyzed by Northern (RNA) blotting of formaldehyde-agarose gels. Twelve separate double-stranded probes (listed by the restriction sites at their ends and numbered as in Fig. 1A; BamHI-SspI, -6 to $-91 ; B a m H I-A p a I,-6$ to $-214 ; B g l \mathrm{II}-$ RsaI, 280 to 427; RsaI-HindIII, 428 to 656; HindIII-ApaLI, 657 to 887; ApaLI-EcoRV, 888 to 1061; EcoRV-SphI, 1062 to 1235; BstXI-ScaI, 1336 to 1569; HincII-ClaI, 1774 to 1959 ; ClaI-BstBI, 1960 to 2160; and Nsi I-PstI, 2239 to 2529) were purified by polyacrylamide gel electrophoresis (PAGE), labeled by random priming, and used to determine the extents of the transcripts. Two single-stranded probes to the entire region were used to determine the orientation of the transcripts. Because the two 1,400-base transcripts could be distinguished only by single-stranded probes, six additional single-stranded probes (given $5^{\prime}$ to $3^{\prime}$, numbered as in Fig. $1 \mathrm{~A} ; 1$ to 120,111 to 1,279 to 215,311 to 215,693 to 888 , and 760 to 657 ) were used. The six short, single-stranded probes were made by primer extension in the presence of $\left[\alpha-{ }^{32} \mathrm{P}\right] \mathrm{dATP}$ on single-stranded DNA followed by cutting with restriction enzyme and purification by denaturing PAGE. Hybridizations were done in the presence of $50 \%$ formamide (according to the manufacturer's instructions), 

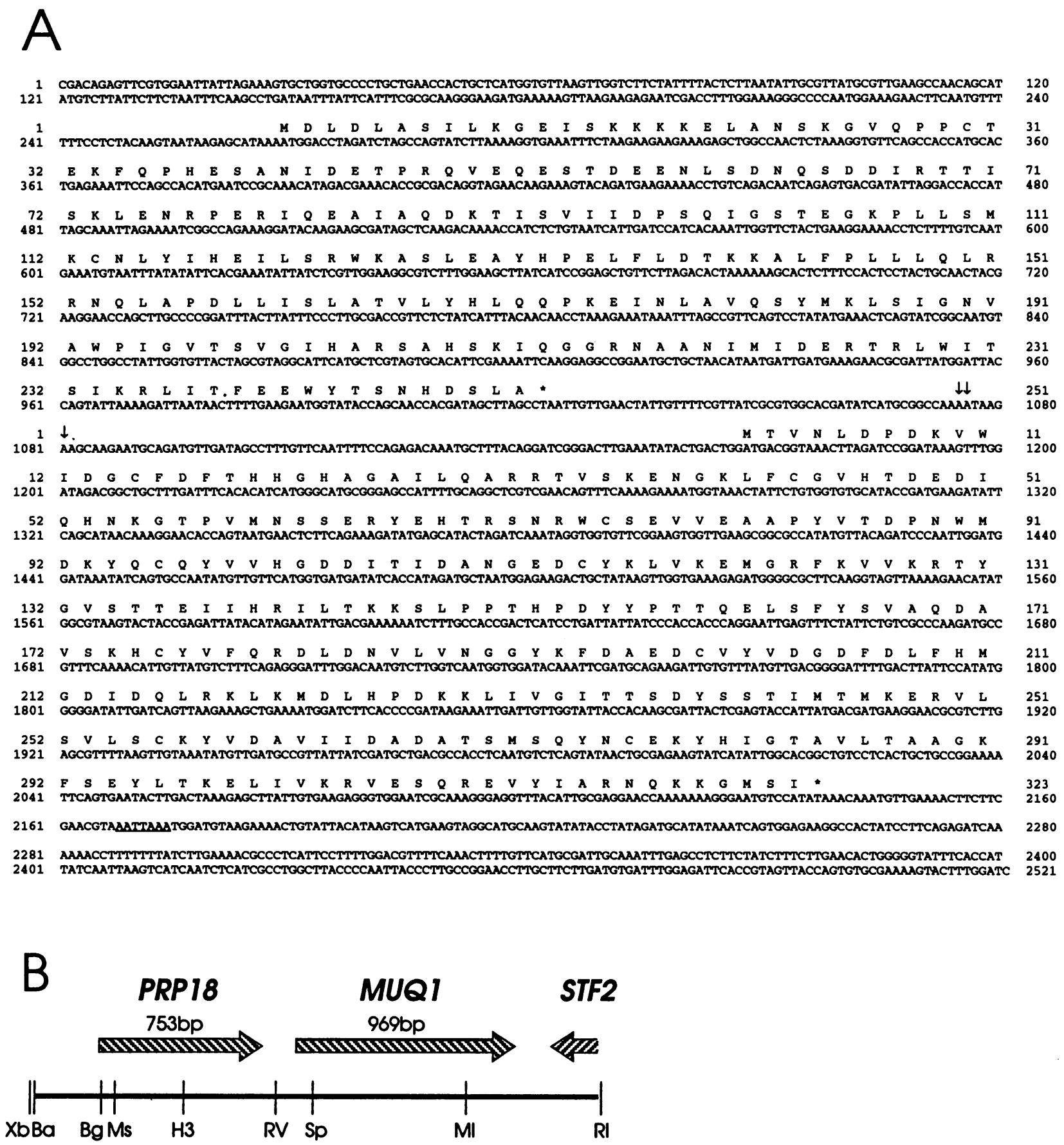

FIG. 1. (A) Sequence of the 2.5-kb complementing fragment (GenBank accession number L03536). Translation of the two long open reading frames is shown. The open reading frame of $P R P 18$ extends from bp 269 through 1021 , that of $M U Q 1$ extends from bp 1168 through 2136, and that of STF2 (not shown in panel A) extends from past the 3' end of the sequence through bp 2312. The mapped start sites of transcription of MUQ1 (transcript D in Fig. 2) are shown by the three arrows near base 1080 . A possible polyadenylation site (for transcripts $A$ and $D$ in Fig. 2) at base 2168 is underscored. (B) Schematic diagram of the sequence. The open reading frames for PRP18, MUQ1, and STF2 are shown by the arrows. Some relevant restriction sites are shown (Xb, XbaI; Ba, BamHI; Bg, BglII; Ms, MscI; H3, HindIII; RV, EcoRV; Sp, SphI; MI, MluI; RI, EcoRI); the XbaI, BamHI, and EcoRI sites are in the polylinker of the vector.

and probed blots were washed for $2 \mathrm{~h}$ at $65^{\circ} \mathrm{C}$ in either $2 \times$ or $0.1 \times \mathrm{SSC}(1 \times \mathrm{SSC}$ is $0.15 \mathrm{M} \mathrm{NaCl}$ plus $0.015 \mathrm{M}$ sodium citrate) to ensure specificity in probing. The data acquired were consistent only with the diagram shown in Fig. 2B. By primer extension, the $5^{\prime}$ end of the 1,200-base transcript was mapped to bases 1075,1076 , and 1081 .
Overproduction and purification of PRP18. pDH105 was constructed by replacing the $X b a I-B g l I I$ fragment in PRP18KS + with the annealed oligonucleotides 5'-CTA GACCATGGACCTA-3' and 3'-TGGTACCTGGATCTAG $-5^{\prime}$. To make pDH111, pAR3039 (65) was cut with NdeI and filled in with Klenow fragment. The 792-bp NcoI-EcoRV 
TABLE 1. Purification of PRP18 from E. coli ${ }^{a}$

\begin{tabular}{|c|c|c|c|c|}
\hline \multirow[b]{2}{*}{ Step } & \multirow{2}{*}{$\begin{array}{c}\text { Protein } \\
\text { (mg) }\end{array}$} & \multicolumn{2}{|c|}{ PRP18 } & \multirow{2}{*}{$\begin{array}{c}\% \\
\text { Yield }\end{array}$} \\
\hline & & $\%$ & $\begin{array}{l}\text { Amt } \\
(\mathrm{mg})\end{array}$ & \\
\hline Crude extract & 85 & 10 & $\sim 9$ & \\
\hline Ammonium sulfate precipitate & 33 & 20 & 8 & 90 \\
\hline DE52-CM52 flowthrough & 11 & 60 & 7 & 70 \\
\hline Red Sepharose & 2 & 90 & 1.8 & 20 \\
\hline Sepharose S & 0.25 & 99 & 0.25 & 3 \\
\hline
\end{tabular}

${ }^{a}$ The purity of PRP18 was estimated from SDS-PAGE; we did not attempt to determine the specific activity of PRP18.

fragment was excised from pDH105, filled in with Klenow fragment, and ligated into the cut pAR3039. pDH111 was placed in E. coli BL21(DE3) (65). After induction with isopropylthiogalactopyranoside (IPTG), about $10 \%$ of the cell protein was PRP18. The identity of the protein was confirmed by $\mathrm{N}$-terminal sequencing of gel-purified protein. Solubility of overproduced PRP18 was determined by the method of Nagai and Thøgersen (47). PRP18 was mostly insoluble when cells were grown at $37^{\circ} \mathrm{C}$ but was completely soluble when cells were grown at $30^{\circ} \mathrm{C}$. PRP18 was monitored during purification by sodium dodecyl sulfate (SDS)PAGE, which was also used to estimate the purity of the protein. PRP18 migrated anomalously in SDS-polyacrylamide gels with an apparent molecular weight of 34,000 . Table 1 shows the results of one purification of PRP18. Cleared lysates of $E$. coli BL21(DE3)/pDH111 were made with lysozyme and Brij 58 as described elsewhere (66). Phenylmethylsulfonyl fluoride, leupeptin, pepstatin A, benzamidine, and aprotinin were included throughout the purification. Nucleic acid was removed from the lysate by precipitation with $0.5 \%$ polyethyleneimine. PRP18 remained in the supernatant and was precipitated with $45 \%\left(\mathrm{NH}_{4}\right)_{2} \mathrm{SO}_{4}$. The pellet was redissolved in buffer A (50 mM Tris [pH 7.5], $2 \mathrm{mM}$ $\beta$-mercaptoethanol, $1 \mathrm{mM}$ EDTA, $10 \%$ [vol/vol] glycerol)-25 $\mathrm{mM} \mathrm{KCl}$ and dialyzed against buffer $\mathrm{A}-25 \mathrm{mM} \mathrm{KCl}$. The dialysate was diluted to $3 \mathrm{mg}$ of protein per $\mathrm{ml}$ with buffer A-25 mM KCl and was loaded onto serial DE52 and CM52 columns. PRP18, about $60 \%$ pure, was recovered in the flowthrough. The PRP18 pool was loaded on a Red Sepharose column and eluted with a gradient of 35 to 1,000 $\mathrm{mM} \mathrm{KCl}$ in buffer A. PRP18 eluted throughout the gradient, peaking at 400 to $600 \mathrm{mM} \mathrm{KCl}$. The peak fractions were pooled, dialyzed against buffer $B$ ( $25 \mathrm{mM}$ morpholinoethanesulfonic acid [MES; pH 6.0], 2 mM $\beta$-mercaptoethanol, 1 $\mathrm{mM}$ EDTA, $10 \%$ [vol/vol] glycerol)-25 mM KCl and loaded onto a Sepharose S column. The column was developed with a 25 to $1,000 \mathrm{mM} \mathrm{KCl-buffer} \mathrm{B} \mathrm{gradient.} \mathrm{PRP18} \mathrm{eluted}$ between 180 and $210 \mathrm{mM} \mathrm{KCl}$. The protein appeared homogeneous on a Coomassie blue-stained gel; silver staining of 1 $\mu \mathrm{g}$ of PRP18 revealed several minor bands. The purified protein was concentrated and dialyzed into buffer A-200 mM $\mathrm{KCl}-50 \%$ (vol $/ \mathrm{vol}$ ) glycerol and stored at $-20^{\circ} \mathrm{C}$. It is stable for at least 1 year. Low yields, probably a result of aggregation of PRP18, were a problem during the purification. Analysis of various fractions by gel filtration showed some aggregates early in the purification. The final product appears to be a dimer with an elution volume corresponding to that of a $53-\mathrm{kDa}(\approx 2 \times 28-\mathrm{kDa})$ protein.

Antibodies to PRP18. Antibodies against gel-purified PRP18 were raised in rabbits. Two antibodies raised $(\alpha A$ and $\alpha B)$ exhibited slightly different properties: $\alpha \mathrm{A}$ reacted better with PRP18 on Western blots and inhibited the second step of splicing more completely than $\alpha \mathrm{B}$, but $\alpha \mathrm{B}$ immunoprecipitated snRNPs better than $\alpha A$. Both antibodies met the specificity criteria described in Results, and affinity-purified antibodies were more similar. PRP18 was detected in Western blots of extracts from wild-type yeast cells by using the High Sensitivity Enzygraphic Web or the ECL system, essentially according to the manufacturers' instructions. For making affinity-purified antibodies, PRP18 was coupled to tresyl-activated agarose, ammonium sulfate-fractionated sera were loaded onto the column, and purified antibodies were eluted sequentially at $\mathrm{pH} 2.5$ and 11.5 (28).

Immunoprecipitation of snRNPs. Yeast extracts for immunoprecipitations were made from strain SS330, EJ101, or CBO18a as described by Lin et al. (42). Immunoprecipitations were carried out essentially as described previously (7) except that preincubation of extracts under splicing conditions was omitted unless specifically indicated; in addition, $\mathrm{KCl}$ was substituted for $\mathrm{NaCl}$ throughout. Northern blotting for the snRNAs was carried out as described previously (17) except that the U6 probe was derived from plasmid pT7U6 (22). Blots were quantitated with a Molecular Dynamics PhosphorImager. U5 snRNA was depleted by addition of a large excess of two oligonucleotides complementary to bases 1 to 24 and to bases 124 to 139 of the U5 snRNA followed by a 30-min incubation at $30^{\circ} \mathrm{C}$ under splicing conditions. About $75 \%$ of the U5 snRNA was cut at least once (40). Labeling of immunoprecipitated RNA with cytidine $3^{\prime}, 5^{\prime}-\left[5^{\prime}-32 \mathrm{P}\right]$ bisphosphate (pCp) was performed as described previously (19).

Splicing reactions. Antibody inhibition of splicing was carried out as described by Banroques and Abelson (7). For the assay of splicing at different temperatures, PRP18depleted extract was prepared as described elsewhere (33). Splicing reactions (42) were run at different temperatures by bringing the extract and the splicing cocktail to the target temperature and then mixing them. Quantitation was done with a Molecular Dynamics PhosphorImager.

Nucleotide sequence accession number. The sequence shown in Fig. 1A has been assigned GenBank accession number L03536.

\section{RESULTS}

Sequence, disruption, and transcription of the PRP18 gene. A 2.5-kb fragment containing the PRP18 gene had been cloned in $S$. cerevisiae by complementation of the prp18 temperature-sensitive phenotype (70). Analysis of the segregation of the prp18 temperature-sensitive allele and a $U R A 3$ gene integrated at the locus of the cloned gene showed that the cloned gene was indeed PRP18 (70). The sequence of the 2.5-kb fragment has been determined and is shown in Fig. 1A. As shown in the schematic diagram in Fig. 1B, the sequenced region contains two open reading frames and part of the previously known $S T F 2$ gene (77). By complementation, we found that the first of the two open reading frames is PRP18; the region bounded by the BamHI site in the vector and the EcoRV site (Fig. 1B) is sufficient to complement the prp18 temperature-sensitive defect, while the region bounded by the HindIII site and the EcoRI site in the vector does not complement.

The PRP18 protein is encoded by bases 269 through 1021 of the sequence (Fig. 1A), giving a nearly neutral (calculated pI of 6.6) protein of 251 amino acids (aa) $(28,400 \mathrm{kDa})$. We found no homology between PRP18 and other proteins in the data base $(2,51)$, nor did we find any known motifs in PRP18 (5). The second open reading frame, named $M U Q 1$, encodes 


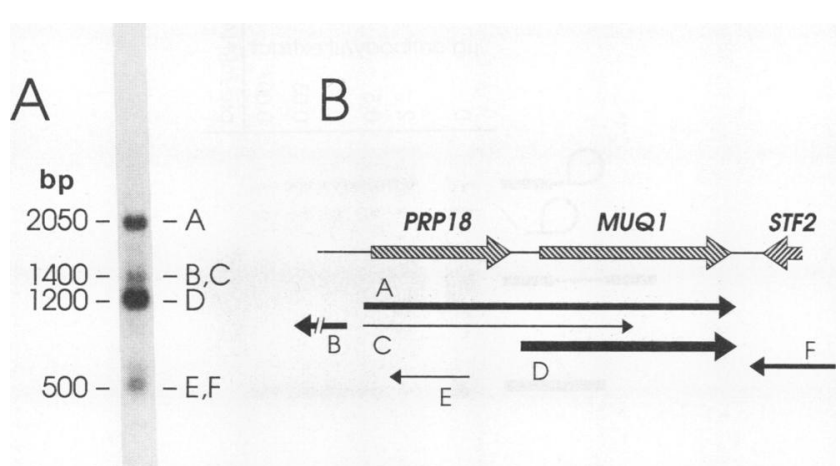

FIG. 2. (A) Northern blot of $4 \mu \mathrm{g}$ of poly(A) ${ }^{+}$RNA, using the entire 2,521-bp fragment as a probe; (B) schematic diagram of the transcription from this region, showing the assignments of the lettered transcripts. At the top of the diagram, the sequenced region of the chromosome and the $P R P 18, M U Q 1$, and $S T F 2$ open reading frames are shown; below (solid arrows) are the various transcripts. More abundant transcripts are indicated as heavier arrows. The presumed open reading frame for transcript B could not be readily identified in our sequence. The estimated molar ratio of the transcripts $D, A$, and $C$ is 5:1:0.1. In Fig. 1A, the start of transcript $D$ is shown by arrows near base 1080 , and a possible polyadenylation site for $A$ and $D$ is underlined. The sequence shows that there are two short open reading frames in the 93-base 5 ' leader of transcript D (ATG-1089 to TGA-1161 and ATG-1130 to TGA-1151). Both short frames terminate just before the start of the $M U Q 1$ coding region at base 1168 .

a protein of 323 aa; MUQ1 has substantial similarity (about $35 \%$ identity in the 138 aa between 7 and 144) to choline phosphate cytidylyltransferase, which has been cloned from yeast (68) and rat (37) cells. (Nearly identical alignments could be made between MUQ1 and either of the homologous proteins.) Disruption of the $M U Q 1$ gene showed that it is not essential.

To determine whether $P R P 18$ is essential, we constructed a yeast strain in which the $P R P 18$ gene was disrupted. First, we made a plasmid (pDH120R) in which the portion of the PRP18 gene between the MscI and HindIII sites (Fig. 1B) was replaced by a $1.8-\mathrm{kb}$ BamHI-Bam HI fragment containing the HIS3 gene (64). The choice of this region of PRP18 for replacement was dictated by the presence of the $M U Q 1$ gene downstream of $P R P 18$ and by another, unidentified gene upstream of PRP18 (Fig. 2B; see also Materials and Methods). The plasmid was used to make a diploid yeast strain in which one copy of the PRP18 gene was disrupted by $H I S 3$ (58). All four spores generated from these yeast cells were viable. However, the $\mathrm{His}^{+}$PRP18-disrupted yeast strain grew very slowly, taking several days to make visible colonies at 23 or $30^{\circ} \mathrm{C}$, and did not grow at all at $37^{\circ} \mathrm{C}$. At $23^{\circ} \mathrm{C}$, these yeast cells accumulated unspliced RNA, consistent with the idea that their slow growth was due to a splicing deficiency. A plasmid bearing only the PRP18 gene could complement the temperature-sensitive defect, showing that the temperature sensitivity was caused by the disruption of $P R P 18$. Although we cannot rule out the possibility that the yeast cells bearing the $P R P 18$ disruption are viable because they make a partially functional fragment of PRP18 protein from the remaining portion of the PRP18 gene, the sequence expected for the disrupted gene shows that only a 68-aa fragment from the C terminus of PRP18 (starting at Met-184) can be made. Our experiments show that yeast cells lacking $P R P 18$ are temperature sensitive, grow slowly, and do not splice pre-mRNA efficiently even at a low temperature. An in vitro experiment consistent with this conclusion is described below.

We analyzed the transcription of the PRP18 and MUQ1 genes and found that several transcripts are made from this region. A Northern blot of the transcripts is shown in Fig. $2 \mathrm{~A}$, and a schematic drawing is shown in Fig. 2B. The major transcript of $P R P 18$ is 2,050 bp (A in Fig. 2) and includes both the $P R P 18$ and the downstream $M U Q 1$ coding regions. This apparently polycistronic transcript is presumably translated to make PRP18, but a second, more abundant transcript (D), spanning only the $M U Q 1$ gene, may be used to make the MUQ1 protein. Transcript D starts only $55 \mathrm{bp}$ from the $3^{\prime}$ end of the $P R P 18$ coding region. A minor transcript (C) apparently spans the PRP18 gene and ends within the $M U Q 1$ gene. We do not know whether this unusually complicated pattern of transcripts has any biological significance.

Overproduction and purification of PRP18 and raising of antibodies to PRP18. To facilitate the study of PRP18, we prepared active PRP18 protein and made antibodies against PRP18. The PRP18 gene was placed under control of the T7 $\phi 10$ promoter (65); in this construction, no alteration was made to the yeast PRP18 coding region. PRP18 was produced at high levels in $E$. coli bearing this plasmid. PRP18 was purified from $E$. coli by ammonium sulfate precipitation and by chromatography on DEAE-cellulose, carboxymethyl cellulose, Red Sepharose, and Sepharose S (Table 1 and Materials and Methods). The protein was $>98 \%$ pure by SDS-PAGE and silver staining (data not shown). Gel filtration results suggested that PRP18 is a dimer in solution. The purified PRP18 is active and restores splicing activity to PRP18-depleted extracts (33).

We have raised antibodies in rabbits to gel-purified PRP18. The antibodies can be used to detect PRP18 in Western blots of extracts from wild-type yeast cells (Fig. 3). PRP18 was identified by its mobility and its absence from extracts of yeast lacking the PRP18 gene (Fig. 3, lane 6). From a comparison of the signal from PRP18 in lanes 1 and 3 of Fig. 3 , we estimate that PRP18 is only $2 \times 10^{-3} \%$ of total yeast protein, corresponding to approximately 2,000 copies per cell. This copy number is comparable to the value of 200 obtained for yeast snRNAs (74). Several other proteins were detected with the $\alpha$ PRP18, even following affinity purification of the antibody. This background probably results from the extreme scarcity of the protein; other PRP proteins have been similarly difficult to detect $(7,35,52)$. The specificity of the antibodies was shown by two experiments; in Western blots of the proteins precipitated by $\alpha$ PRP18, only PRP18 was detected (not shown), and the splicing activity of extracts immunodepleted of PRP18 was restored by addition of purified PRP18 protein, showing that only PRP18 was depleted (33). Affinity-purified antibodies were used in some experiments to verify the specificity of the antibody.

The antibodies inhibited splicing (Fig. 4). The second step of splicing was substantially, but not completely, inhibited; 2/3 lariat and exon 1 intermediates accumulated, and there was a corresponding reduction in the amount of mRNA produced. With large amounts of antibody, there was some, likely nonspecific, inhibition of the first step (Fig. 4). A vast excess of antibody was necessary to achieve good inhibition; similar amounts were required in analogous experiments with other splicing proteins $(7,16,52)$. The inhibition could be reversed by the addition of excess purified PRP18 protein (data not shown). We have also carried out splicing in extracts which had been immunodepleted of PRP18 (described in reference 33; see also Fig. 7). Analysis of the 


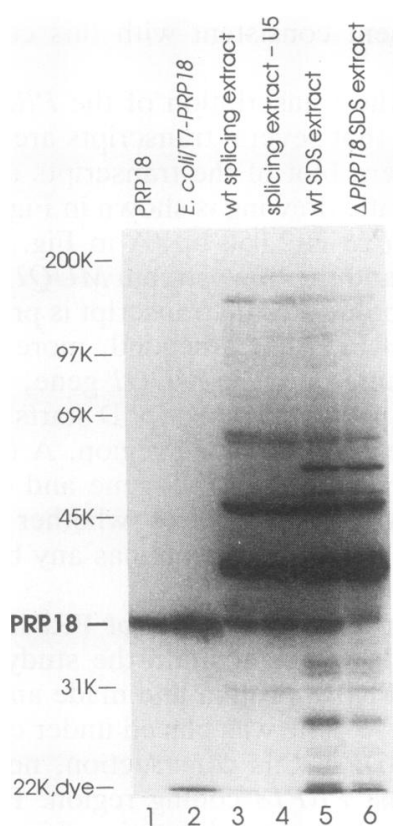

FIG. 3. Western blot of yeast extracts with affinity-purified $\alpha$ PRP18. Lanes: $1,100 \mathrm{pg}$ of purified PRP18; 2, approximately $2 \mathrm{ng}$ of total protein from $E$. coli overexpressing the PRP18 protein [BL21(DE3)/pDH111 induced with IPTG]; 3, $10 \mu \mathrm{g}$ of yeast protein from a splicing extract from strain $\mathrm{CBO} 18 ; 4,10 \mu \mathrm{g}$ of yeast protein from a splicing extract of a strain in which the U5 gene had been turned off; 5 , total protein from a zymolyase-SDS lysis of yeast strain SS330; 6, total protein from a zymolyase-SDS lysis of yeast strain DH120R-1, in which the PRP18 gene had been disrupted. For this blot, affinity-purified antibody was used; PRP18 could also be detected with $\alpha$ PRP18, but several additional proteins were also detected. Some of the bands seen were also detected with the preimmune serum or when the primary antibody was omitted. PRP18 in yeast extracts appeared to have a slightly lower electrophoretic mobility than does PRP18 from $E$. coli; this difference may result from the large difference in the amounts of protein loaded in lanes 1 and 3 . wt, wild type.

kinetics of splicing in these extracts shows that depletion of PRP18 inhibits only the second step of splicing (33). Inhibition of the second step is incomplete in depleted extracts, consistent with the idea that PRP18 is not absolutely required for splicing.

Immunoprecipitation of snRNPs. To determine whether PRP18 is associated with any of the snRNPs involved in splicing, we carried out a series of immunoprecipitation experiments with $\alpha$ PRP18. Antibodies directed against the PRP4 protein were used as positive controls in our experiments; PRP4 is a yeast U4 snRNP protein $(7,11,52,75)$. Yeast extracts were incubated with antibody bound to protein A-Sepharose; bound RNA was extracted and run on a denaturing gel, which was probed for the U1, U2, U4, U5, and U6 snRNAs. Results of such an experiment are shown in Fig. 5. $\alpha$ PRP18 precipitated the U4, U5 (both $\mathrm{S}$ and $\mathrm{L}$ forms), and U6 snRNAs from a yeast extract. About $8 \%$ of the U4, $5 \%$ of the U5, and $4 \%$ of the U6 snRNAs were precipitated; these recoveries were somewhat lower than those seen in $\alpha$ PRP4 immunoprecipitations. The specificity of this precipitation was shown by several results. First, none of the snRNAs was precipitated by preimmune serum (Fig. 5), and the same snRNAs were precipitated by affinitypurified antibody (not shown). Second, the precipitation was

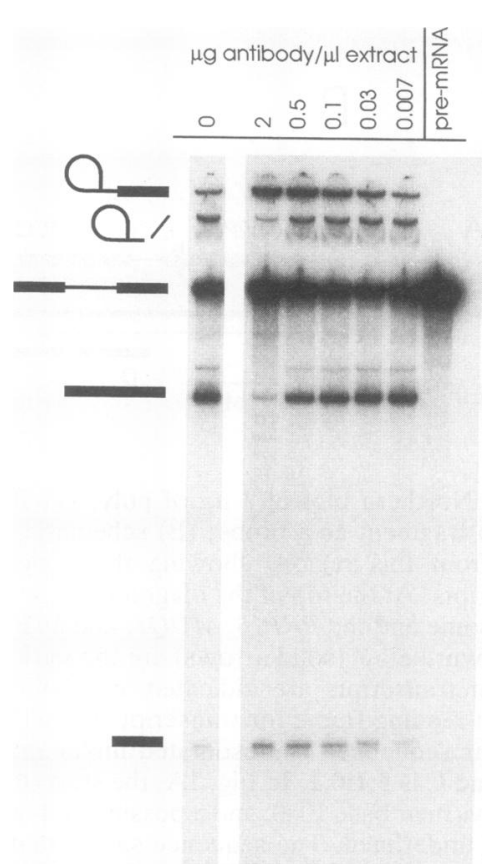

FIG. 4. Inhibition of splicing by affinity-purified $\alpha$ PRP18. Shown is splicing of pre-mRNA following incubation with different amounts of antibody as indicated. The positions of $2 / 3$ lariat, intron, premRNA, mRNA, and exon 1 are indicated by symbols. Splicing could be similarly inhibited with protein A-purified antibody, although more antibody was required.

stable at moderate salt concentrations. At $50 \mathrm{mM} \mathrm{KCl}$, there was some nonspecific precipitation of U1 and U2 (Fig. 5) as well as other RNA (determined by pCp labeling [7, 75]), but between 100 and $300 \mathrm{mM} \mathrm{KCl}$, the precipitation of $\mathrm{U} 4$, U5, and U6 showed only a small salt sensitivity (Fig. 5). Immunoprecipitation of $\mathrm{U} 4, \mathrm{U} 5$, and $\mathrm{U} 6$ was also resistant to heparin (not shown), which is effective in disrupting nonspecific RNA-protein interactions $(7,17)$. Finally, we have labeled the immunoprecipitated RNAs with pCp (data not shown). U4, U5S, and U5L were detected; U6 cannot be labeled with pCp (45). Several other RNAs were also detected at about the same level as the U RNAs, but these varied in precipitations from different extracts (also seen in the studies reported in references 43 and 52). The pattern of pCp labeling of RNAs precipitated by $\alpha$ PRP18 was identical to that of RNAs precipitated by $\alpha$ PRP4, which had been shown to precipitate U4, U5, and U6 snRNAs. All of the data show that U4, U5, and U6 snRNAs are precipitated specifically by $\alpha$ PRP18.

The U4, U5, and U6 snRNPs are thought to form a single particle $(17,39)$; hence, the precipitation of all three snRNAs by $\alpha$ PRP18 might result from interaction between PRP18 and only one snRNP. We used two types of experiments to characterize the interactions between PRP18 and the snRNPs further. First, we performed immunoprecipitations at different salt concentrations or in the presence of ATP; second, we immunoprecipitated snRNAss from extracts which had been depleted of specific snRNAs. The precipitation of U4, U5, and U6 was not significantly affected by increasing the salt concentration from 100 to $300 \mathrm{mM}$; however, above $300 \mathrm{mM}$ there was a sharp decrease in the precipitation of all of the snRNAs (Fig. 5). Precipitation of all three snRNAs declined at the same rate as the $\mathrm{KCl}$ 


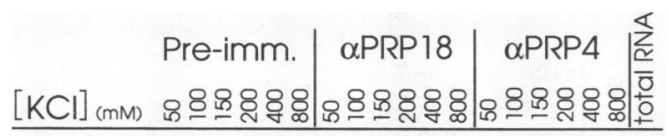

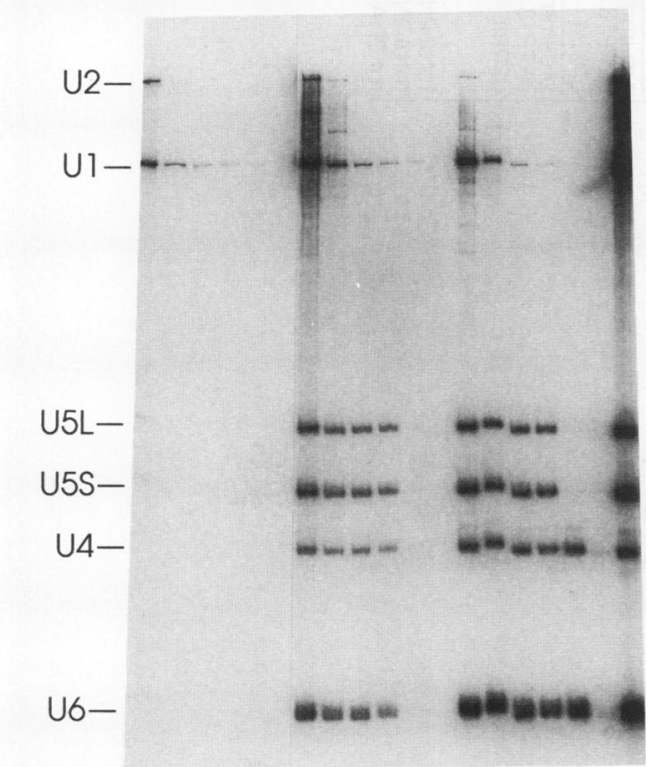

FIG. 5. Salt dependence of the immunoprecipitation of snRNAs. Immunoprecipitations from yeast extracts were carried out with preimmune antibody, $\alpha P R P 18$, or $\alpha$ PRP4 as described in the text. The salt concentration was varied as indicated. The recovered RNAs were detected by Northern blotting with DNA complementary to the U1, U2, U4, U5, and U6 snRNAs.

concentration was increased from 300 to $400 \mathrm{mM}$ (data not shown). This decrease paralleled the decline in precipitation of U5 snRNA by $\alpha$ PRP4 (Fig. 5) (7). We also tried to find preferential precipitation of one of the snRNAs by preincubating extracts under splicing conditions with ATP, which is thought to affect the conformation of the U4/U5/U6 snRNP $(10,17,39)$, or by adding heparin to the extracts. Neither of these changes individually affected the immunoprecipitation, but inclusion of both ATP and heparin sharply reduced the amounts of all the snRNAs precipitated (also observed with $\alpha$ PRP4 [7]). We did not see preferential precipitation of any of the snRNAs under any conditions.

We carried out immunoprecipitations with $\alpha$ PRP18 from yeast extracts which had been depleted of either U5 or U6 snRNA. A U6-depleted extract was made in vitro by using a deoxyoligonucleotide and RNase $\mathrm{H}$ (22). From this extract, $\alpha$ PRP18 precipitated normal amounts of both U4 and U5 (Fig. 6A) but very little U6. Added T7-transcribed U6 RNA can be assembled into snRNP (22) and was precipitated by $\alpha$ PRP18 (Fig. 6A). This experiment shows that PRP18 binding to U4 and U5 does not require U6 and suggests that PRP18 does not interact with the U6 snRNP. $\alpha$ PRP4 precipitates U4 and U5 following depletion of U6, suggesting that $\mathrm{U} 4$ and $\mathrm{U} 5$ remain associated after destruction of U6 in yeast extracts (6); similar results were found in HeLa extracts (10).

A U5-depleted extract was made from a yeast strain in which expression of the U5 snRNA could be regulated (50). Splicing extract was made from this strain several generations after the U5 gene had been turned off, leading to a 15-fold depletion of U5 (Fig. 6B) (40, 50, 61). aPRP18 precipitated only trace amounts of snRNAs from the U5depleted extract (Fig. 6B). Several results show that the failure of $\alpha \mathrm{PRP} 18$ to precipitate snRNPs from this extract is a direct consequence of the absence of U5 and not a result of any other problems with this extract. First, Krinke and Abelson (40) have shown that some splicing activity can be restored to U5-depleted extracts by the addition of U5 snRNA, suggesting that the extract is otherwise competent for splicing (see also reference 61). A small amount of added, T7-transcribed U5 could be precipitated by $\alpha$ PRP18 or by $\alpha$ PRP4 (Fig. 6B). Second, PRP18 is present at wild-type levels in this extract and was seen in Western blots (Fig. 3, lane 4). Third, aPRP4 precipitated both U4 and U6 snRNAs from the U5-depleted extract, although the ratio of U4 to U6 was higher than in wild-type extracts. Finally, a procedure for partially depleting U5 snRNA by using two deoxyoligonucleotides has been developed by Krinke and Abelson (40). Precipitation of U4, U5, and U6 from this extract by $\alpha$ PRP18 is reduced, consistent with the previous result. In summary, our results show that PRP18 binding to the U4/U5/U6 snRNP requires U5 but not U6 and hence that PRP18 is likely part of the U5 snRNP.

We were not able to carry out a depletion of the U4 snRNA. Only one oligonucleotide has been reported to facilitate RNase $\mathrm{H}$ cleavage of the yeast U4 snRNA (75), but destruction of U4 with this oligonucleotide does not abolish splicing activity (21). It seems unlikely a priori that PRP18 interacts primarily with $\mathrm{U} 4$, since $\mathrm{U} 4$ leaves the spliceosome before PRP18 acts (76). The failure of $\alpha$ PRP18 to precipitate $\mathrm{U} 4$ in the absence of U5 confirms this idea.

Splicing at different temperatures in a PRP18-depleted extract. Two findings, that PRP18 is essential only for viability at high temperatures and that extracts immunodepleted of PRP18 retain some splicing activity (33), suggested to us that a PRP18-depleted extract might have no splicing activity at high temperatures. Correlations between in vivo and in vitro requirements for PRP proteins have been seen for several other proteins (46). We assayed splicing in a PRP18-depleted extract (33) at different temperatures. Results of assays of splicing at $16,23,28$, and $32^{\circ} \mathrm{C}$ using preimmune antibody-depleted and $\alpha$ PRP18-depleted extracts are shown in Fig. 7A. At each temperature, three time points were analyzed; the times selected at each temperature were different to account for differences in the reaction rates. Under standard splicing conditions $\left(23^{\circ} \mathrm{C}\right)$, depletion of PRP18 greatly reduces the amount of mRNA produced (33). The amount of mRNA made in the PRP18-depleted extract declined substantially as the temperature was increased from 16 to $32^{\circ} \mathrm{C}$; mRNA was nearly undetectable in the $32^{\circ} \mathrm{C}$ reactions. In the parallel reactions using preimmune antibody-depleted extract, there was also a decrease in the amount of mRNA produced, but this decrease was much smaller than that seen in the $\alpha$ PRP18-depleted extracts.

In the absence of a well-defined kinetic model for splicing, it is not possible to give a definitive interpretation of these results. However, the following argument supports the idea that the PRP18-depleted extract is temperature sensitive for the second step of splicing. (The analysis of splicing kinetics is discussed in more detail in reference 33.) Quantitative analysis of the gel shown in Fig. 7A demonstrated that the first step of splicing was unaffected by depletion of PRP18 at all temperatures. Both the amounts of pre-mRNA and the amounts of products, defined as RNA beyond the first step of splicing, showed this result. The rate of the second step $\left(k_{2}\right)$ can be estimated from the time course shown in Fig. 7A, as described in the figure legend; the two rate constants, $k_{2}$ (pre) and $k_{2}(\alpha P R P 18)$, are graphed as functions of the temperature in Fig. 7B. While $k_{2}$ (pre) increased monotoni- 


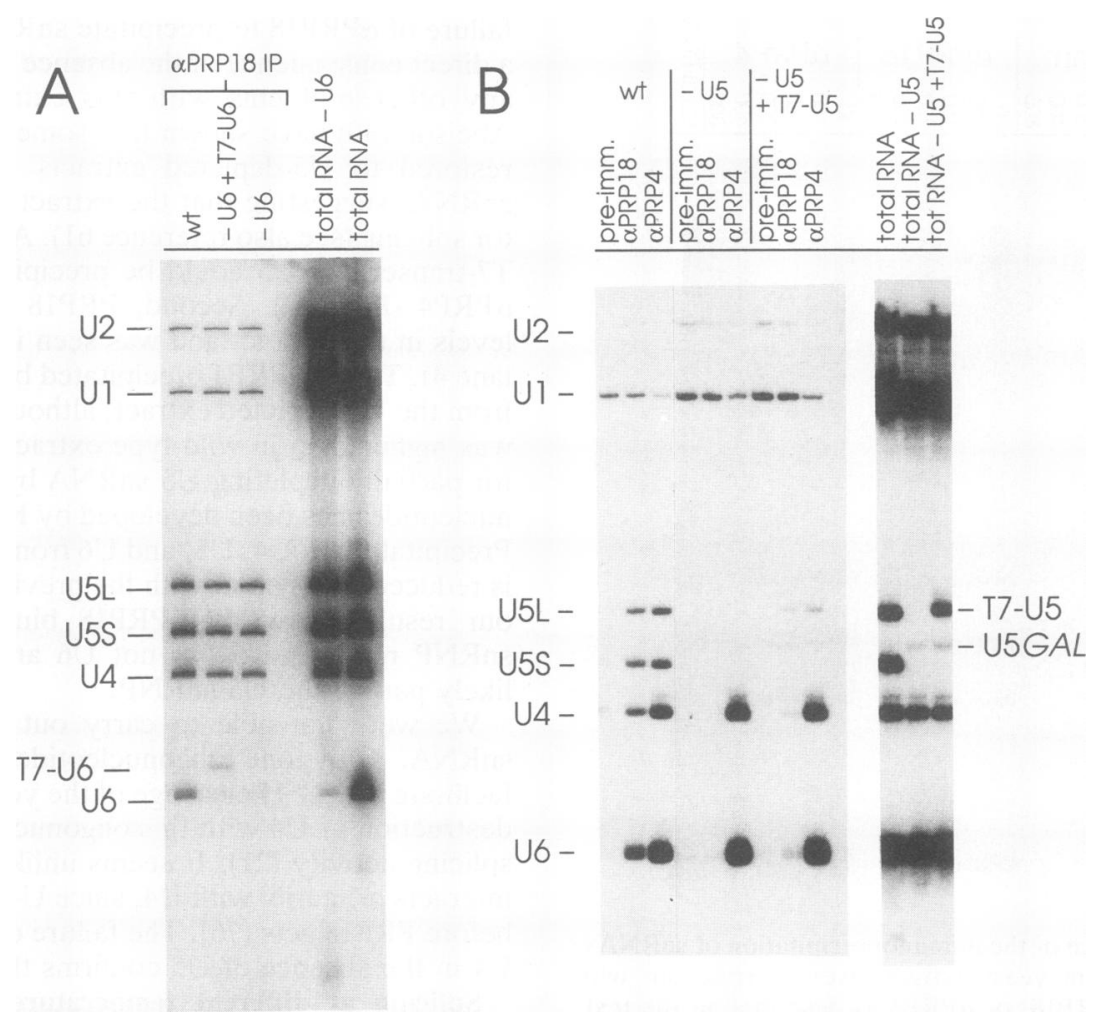

FIG. 6. (A) Immunoprecipitation by $\alpha$ PRP18 from a U6-depleted extract, carried out at $150 \mathrm{mM} \mathrm{KCl}$. About $95 \%$ of the U6 was degraded in the presence of the oligonucleotide. Immunoprecipitations from a control (wild-type [wt]) extract, a U6-depleted extract, and a U6-depleted extract to which T7-transcribed U6 had been added are shown; total RNA from a wild-type extract and a U6-depleted extract are also shown. The RNAs were detected by Northern blotting. (B) Immunoprecipitation by preimmune antibodies, $\alpha$ PRP18, and $\alpha$ PRP4 from a U5-depleted extract, carried out at $150 \mathrm{mM} \mathrm{KCl}$. About $8 \%$ of the normal level of U5 (comparing GAL-U5 with normal levels of U5S plus U5L) was present. Shown are immunoprecipitations from a wild-type extract, an extract depleted of U5 snRNA in vivo, and an extract from the U5-depleted extract to which T7-transcribed U5 had been added. In this assay, $1.5 \%$ of the T7-transcribed U5 could be precipitated by $\alpha \mathrm{PRP} 18$; about $6 \%$ of the U5 was precipitated from corresponding wild-type extracts.

cally with increasing temperature, $k_{2}(\alpha \mathrm{PRP} 18)$ fell with increasing temperature. The ratio of $k_{2}(\alpha \mathrm{PRP} 18)$ to $k_{2}(\mathrm{pre})$ was $4 \times 10^{-2}$ at $16^{\circ} \mathrm{C}$ and fell continuously to $3 \times 10^{-3}$ at $32^{\circ} \mathrm{C}$. Hence, there was a 15 -fold reduction in the relative rate of splicing as the temperature was increased from 16 to $32^{\circ} \mathrm{C}$. From this reasoning, we believe that the PRP18depleted extract is temperature sensitive for the second step of splicing.

We wondered whether a PRP18-depleted extract could be irreversibly heat inactivated by heating at $32^{\circ} \mathrm{C}$. The PRP18depleted extract was heated to $32^{\circ} \mathrm{C}$ for $20 \mathrm{~min}$ and then immediately assayed for splicing activity at $23^{\circ} \mathrm{C}$ (Fig. 7A). Both steps of the splicing reaction were slowed by approximately twofold, but no specific inactivation of the second step was seen, implying that the change in the extract which leads to inhibition of the second step of splicing at $32^{\circ} \mathrm{C}$ was reversible. Heat inactivation of extracts from a prp18 temperature-sensitive strain had been reported previously (70). Since the defect in the prp18 gene in this strain is not presently known, our results cannot be directly compared with this heat inactivation result.

\section{DISCUSSION}

The PRP18 gene was discovered in a screen of a bank of temperature-sensitive yeast strains for splicing mutants (71), and initial work on PRP18 showed that it was involved in the second step of splicing $(70,71)$. In the present work, we have demonstrated that PRP18 is a component of the U4/U5/U6 snRNP, binding principally to the U5 snRNP. We also have showed that PRP18 is not absolutely required for splicing at low temperatures but is required at higher temperatures. In a separate report, we will demonstrate that PRP18 is involved only in the second step of splicing. In extracts depleted of PRP18, intermediates in the splicing pathway accumulate; these intermediates can be chased to products by the addition of PRP18 in the presence or absence of ATP (33).

We have sequenced the PRP18 gene and found a 753-bp coding region that does not show similarity to other genes in the data bases. We constructed a disruption of the PRP18 gene and found that haploid yeast cells bearing only a disrupted copy of the PRP18 gene were temperature sensitive for growth. These yeast cells grew very slowly and accumulated unspliced RNAs at $23^{\circ} \mathrm{C}$, as did the previously reported prp18 temperature-sensitive strains (70). The temperature sensitivity of splicing in the absence of PRP18 could be reproduced in vitro. Yeast extracts immunodepleted of PRP18 were able to splice pre-mRNA at low temperature $\left(23^{\circ} \mathrm{C}\right)$, albeit inefficiently; however, at high temperature $\left(32^{\circ} \mathrm{C}\right)$, little or no mRNA was produced. Only the second step of the splicing reaction was affected by the depletion of PRP18 at any temperature. Both the in vitro and in vivo results suggest that PRP18 is not required for splicing at low 


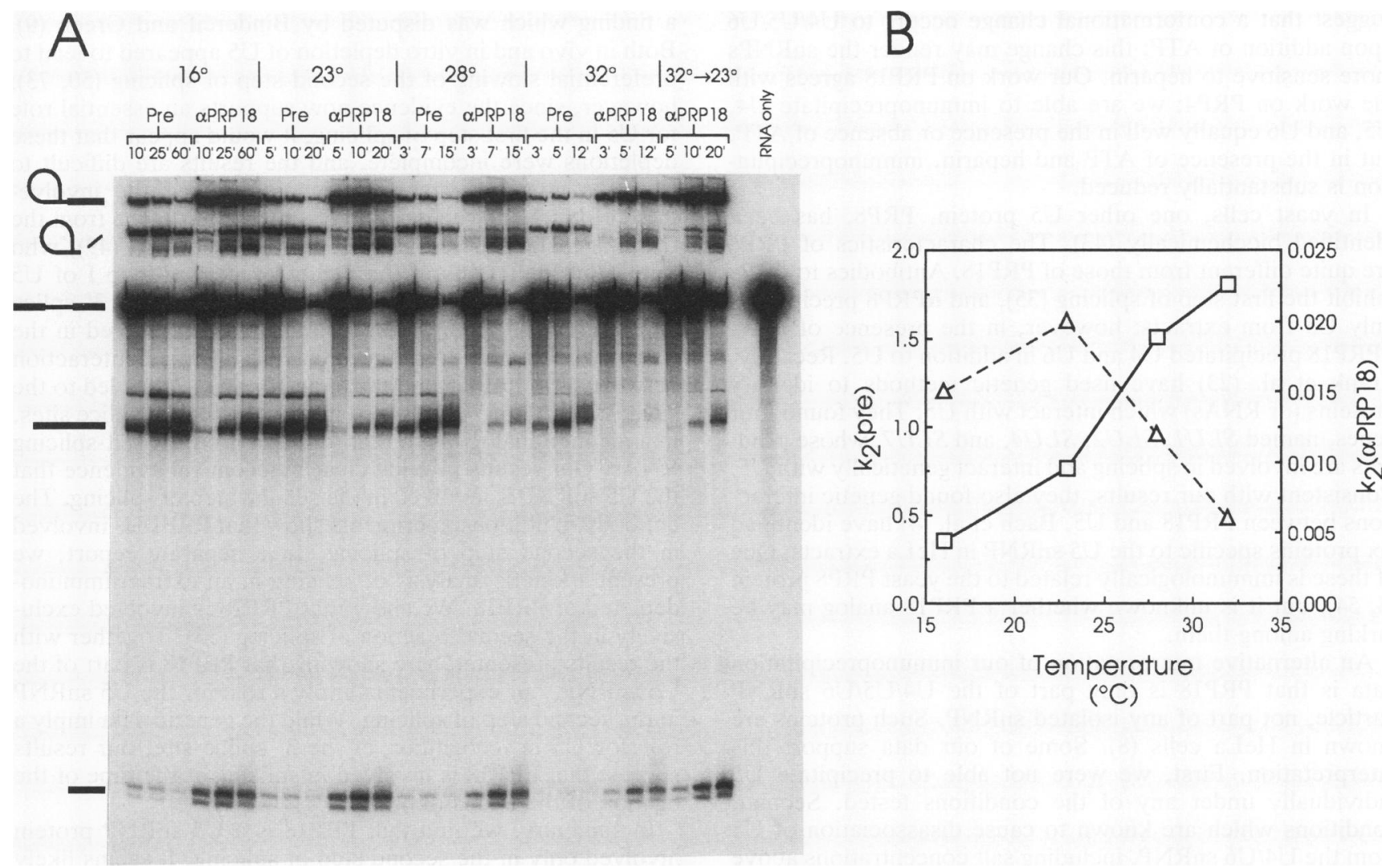

FIG. 7. (A) Assay of splicing in preimmune antibody-depleted and $\alpha$ PRP18-depleted extracts. The positions $2 / 3$ lariat intermediate, intron lariat, pre-mRNA, mRNA, and the exon 1 intermediate are indicated symbolically at the left. The temperature and duration (in minutes) of each splicing reaction are indicated above the lanes. For the three lanes marked $32^{\circ} \rightarrow 23^{\circ}$, PRP18-depleted extract was heated to $32^{\circ} \mathrm{C}$ for 20 min and then assayed for splicing at $23^{\circ} \mathrm{C}$. (B) Rate constants. The rate constants $k_{2}$ (pre) (squares) and $k_{2}(\alpha P R P 18)$ (triangles) were estimated as follows. We assumed that $d$ [mRNA] $/ d t=k_{2}[2 / 3$ lariat] (assuming that the second step is essentially a unimolecular reaction and neglecting degradation). Approximating $d[\mathrm{mRNA}] / d t$ by $\Delta[\mathrm{mRNA}] / \Delta t$ leads to $\Delta[\mathrm{mRNA}] / \Delta t \approx k_{2}[2 / 3$ lariat]. The average value of $[2 / 3$ lariat] over the interval $\Delta t$ was calculated from PhosphorImager data for this gel, leading to a value for each $k_{2}$. We used the first and second time points in each case for calculating the rate constants. A very similar conclusion can be reached from comparisons of $\Delta[\mathrm{mRNA}] / \Delta t$ at different temperatures.

temperatures, although the second step of splicing is substantially slowed in its absence. At high temperatures, PRP18 is necessary for the second step of splicing. This finding can be interpreted in two ways. Either the role that PRP18 plays in splicing is itself essential only at high temperatures or its role is essential at all temperatures, but another protein (or RNA) can inefficiently substitute for PRP18 at low temperatures. Temperature sensitivity of null mutants is rare, although it has been found for several proteins involved in vacuolar protein sorting $(30,55)$. Because several genes in this pathway exhibit this phenotype, it has been hypothesized that the process of vacuolar protein sorting is required only at high temperatures.

A series of immunoprecipitation experiments showed that PRP18 is an snRNP protein. $\alpha$ PRP18 precipitated the U4/ U5/U6 snRNP complex at low or moderate salt concentrations. Extracts depleted of one of the snRNAs were used to determine whether PRP18 is a component of only one of the U4, U5, and U6 snRNPs. U4 and U5 could be precipitated by $\alpha$ PRP18 from extract depleted of U6 snRNA, while no snRNAs could be precipitated from extract depleted of U5 snRNA. We inferred that PRP18 is likely to be part of the U5 snRNP; since we were not able to immunoprecipitate U5 snRNP alone in our experiments, it is possible that PRP18 is only part of the U4/U5/U6 snRNP, not part of the isolated U5 SnRNP.

The immunoprecipitation data suggest that PRP18 is not tightly bound to the U5 snRNP. Above $350 \mathrm{mM} \mathrm{KCl}$, no snRNAs can be precipitated by $\alpha$ PRP18. In contrast, three other yeast snRNP proteins $(1,7,52,62)$, as well as the HeLa common snRNP proteins $(32,38)$, remain bound to the snRNPs at much higher salt concentrations. The binding of PRP18 to U4, U5, and U6 was unaffected by ATP. The effect of ATP on the stability and formation of the U4/U5/U6 snRNP complex is not clear. In yeast cells, fractionation of snRNPs on nondenaturing gels (17) or by glycerol gradients (11) showed partial or complete (in the presence of heparin) dissociation of U4/U6 from U5 upon addition of ATP. Studies with antibody to PRP8, a yeast U5 protein, found that U4/U6 was bound to U5 only in the presence of ATP (43); this result is in accord with initial studies of HeLa snRNPs using glycerol gradients (10). Work on PRP4 suggested only a small effect of ATP on U4/U5/U6 stability; however, in the presence of heparin, ATP apparently caused U5 to dissociate from U4/U6, since U5 could no longer be precipitated by $\alpha$ PRP4 (7). Work using purified U4/U5/U6 snRNP from HeLa cells found no effect of ATP on U4/ U5/U6 formation and stability (8). These disparate results 
suggest that a conformational change occurs to U4/U5/U6 upon addition of ATP; this change may render the snRNPs more sensitive to heparin. Our work on PRP18 agrees with the work on PRP4; we are able to immunoprecipitate U4, $\mathrm{U} 5$, and U6 equally well in the presence or absence of ATP, but in the presence of ATP and heparin, immunoprecipitation is substantially reduced.

In yeast cells, one other U5 protein, PRP8, has been identified biochemically (43). The characteristics of PRP8 are quite different from those of PRP18. Antibodies to PRP8 inhibit the first step of splicing (35), and $\alpha$ PRP8 precipitates only U5 from extracts; however, in the presence of ATP, $\alpha$ PRP18 precipitated U4 and U6 in addition to U5. Recently, Frank et al. (23) have used genetic methods to identify proteins (or RNAs) which interact with U5. They found four genes, named $S L U 1, S L U 2, S L U 4$, and $S L U 7$, whose products are involved in splicing and interact genetically with U5. Consistent with our results, they also found genetic interactions between PRP18 and U5. Bach et al. (4) have identified six proteins specific to the U5 snRNP in HeLa extracts. One of these is immunologically related to the yeast PRP8 protein $(3,54)$, but it is unknown whether a PRP18 analog may be lurking among them.

An alternative interpretation of our immunoprecipitation data is that PRP18 is only part of the U4/U5/U6 snRNP particle, not part of any isolated snRNP. Such proteins are known in HeLa cells (8). Some of our data support this interpretation. First, we were not able to precipitate U5 individually under any of the conditions tested. Second, conditions which are known to cause disassociation of U5 from the U4/U6 snRNP, including salt concentrations above $350 \mathrm{mM}(7,8)$ or incubations in the presence of ATP and heparin, greatly reduced the amount of precipitation of all snRNPs; the salt concentration above which $\alpha$ PRP18 no longer precipitates snRNPs is the same as that above which $\alpha$ PRP4 no longer precipitates U5 snRNA. One result which is apparently not consistent with this interpretation is that $\alpha$ PRP18 still precipitated U4 and U5 when U6 had been depleted, suggesting that intact U4/U5/U6 is not required for snRNP binding by PRP18. Behrens and Lührmann (8) have recently found five proteins which are present only in the U4/U5/U6 snRNP. These five proteins appear to be sufficient to promote the assembly of the U4/U5/U6 snRNP from purified U4/U6 and U5 snRNPs. One of these proteins is apparently labile during heat shock, and its absence is responsible for the absence of splicing in heat-shocked cells (69). From the fractionation of these proteins, it appears that they dissociate from the snRNPs at moderate salt concentrations (less than $500 \mathrm{mM}$ ). If PRP18 is indeed specific to the $\mathrm{U} 4 / \mathrm{U} 5 / \mathrm{U} 6$ particle, then it is plausible that an analog of it may be found among these five proteins.

Although U5 snRNP has long been presumed to be involved in splicing, its role in splicing has been difficult to establish. U5 snRNP was found to be associated with the spliceosome (25), and native gel experiments suggested that U5 joined the spliceosome with U4/U6 before the first reaction in splicing $(9,17,39,53)$. The requirement for U5 in splicing was shown first by genetic experiments in yeast cells (50). Recent results support the notion that U5 is involved early in splicing. First, in extracts depleted of U5 snRNP, only early splicing complexes, lacking U4 and U6, form (41, 61). Second, suppression of mutations in the $5^{\prime}$ splice site by mutations in loop I of the U5 snRNA implies a role for U5 in $5^{\prime}$ splice site recognition (48).

A role for U5 in the second step of splicing was suggested by the $3^{\prime}$ splice site binding experiments of Chabot et al. (15), a finding which was disputed by Bindereif and Green (9). Both in vivo and in vitro depletion of U5 appeared to lead to preferential slowing of the second step of splicing $(50,73)$; however, since the evidence now supports an essential role for U5 in the first step of splicing, it would appear that these depletions were incomplete, and the results are difficult to interpret unambiguously. Evidence favoring the involvement of U5 in the second step of splicing has come from the recent genetic studies of Newman and Norman (49), who found that mutations in the highly conserved loop I of U5 suppress mutations in the AG dinucleotide at the $3^{\prime}$ splice site. Their results imply that U5 snRNA is involved in the recognition of the $3^{\prime}$ splice site. The inferred interaction between loop I of U5 and the $5^{\prime}$ and $3^{\prime}$ splice sites led to the suggestion that U5 is involved in juxtaposing the splice sites, in a manner analogous to that found in group II self-splicing RNAs. Our results provide clear biochemical evidence that the U5 snRNP is involved in the second step of splicing. The antibody inhibition experiments show that PRP18 is involved in the second step of splicing. In a separate report, we present a kinetic analysis of splicing in an extract immunodepleted of PRP18. We show that PRP18 is involved exclusively in the second reaction of splicing (33). Together with the results presented here showing that PRP18 is part of the U5 snRNP, our experiments imply a role for the U5 snRNP in the second step of splicing. While the genetic data imply a role for U5 in recognition of the $3^{\prime}$ splice site, our results suggest that PRP18 is involved in splicing at the time of the ligation of the exons (33).

In summary, we find that PRP18 is a U5 snRNP protein involved only in the second step of splicing. It seems likely that PRP18 does not have a catalytic activity but is a structural snRNP protein. From the unusual temperature sensitivity of yeast cells lacking PRP18, we surmise that the role of PRP18 is to stabilize a conformation that is otherwise unstable at the nonpermissive temperature. The function of PRP18, then, might be to stabilize a particular conformation of the U5 snRNP or to orient the U5 snRNP within the U4/U5/U6 snRNP or within the spliceosome.

\section{ACKNOWLEDGMENTS}

We thank Usha Vijayraghavan for construction of the deletions used in sequencing, Lothar Krinke for providing U5-depleted extract, Josette Banroques, Mahshid Company, Patrizia Fabrizio, Adrian Krainer, R.-J. Lin, Donald Morisato, and Christine O'Day for helpful discussions during this work and for comments on the manuscript, Dan Frank for communication of results prior to publication, and Joyce Kato for assistance in preparation of the manuscript.

D.S.H. was supported in part by Damon Runyon-Walter Winchell Cancer Research Fund grant DRG-924. This work was supported by National Institutes of Health grant GM32367.

\section{REFERENCES}

1. Abovich, N., P. Legrain, and M. Rosbash. 1990. The yeast PRP6 gene encodes a U4/U6 small nuclear ribonucleoprotein particle (snRNP) protein, and the $P R P 9$ gene encodes a protein required for U2 snRNP binding. Mol. Cell. Biol. 10:6417-6425.

2. Altschul, S. F., W. Gish, W. Miller, E. W. Myers, and D. J. Lipman. 1990. Basic local alignment search tool. J. Mol. Biol. 215:403-410.

3. Anderson, G. J., J. D. Beggs, and M. Bach. 1989. Conservation between yeast and man of a protein associated with U5 small nuclear ribonucleoprotein. Nature (London) 342:819-821.

4. Bach, M., G. Winkelmann, and R. Lührmann. 1989. 20S small nuclear ribonucleoprotein U5 shows a surprisingly complex protein composition. Proc. Natl. Acad. Sci. USA 86:6038-6042.

5. Bairoch, A. 1992. PROSITE: a dictionary of sites and patterns in 
proteins. Nucleic Acids Res. 20:2013-2018.

6. Banroques, J., and J. Abelson. Unpublished results.

7. Banroques, J., and J. N. Abelson. 1989. PRP4: a protein of the yeast U4/U6 small nuclear ribonucleoprotein particle. Mol. Cell. Biol. 9:3710-3719.

8. Behrens, S.-E., and R. Lührmann. 1991. Immunoaffinity purification of a [U4/U6.U5] tri-snRNP for human cells. Genes Dev. 5:1439-1452.

9. Bindereif, A., and M. R. Green. 1987. An ordered pathway of snRNP binding during mammalian pre-mRNA splicing complex assembly. EMBO J. 6:2415-2424.

10. Black, D. L., and A. L. Pinto. 1989. U5 small nuclear ribonucleoprotein: RNA structure analysis and ATP-dependent interaction with U4/U6. Mol. Cell. Biol. 9:3350-3359.

11. Bordonné, R., J. Banroques, J. Abelson, and C. Guthrie. 1990. Domains of yeast U4 spliceosomal RNA required for PRP4 protein binding, snRNP-snRNP interactions, and pre-mRNA splicing in vivo. Genes Dev. 4:1185-1196.

12. Bringmann, P., B. Appel, J. Rinke, R. Reuter, H. Theissen, and R. Lührmann. 1984. Evidence for the existence of snRNAs U4 and $\mathrm{U} 6$ in a single ribonucleoprotein complex and for their association by intermolecular base pairing. EMBO J. 3:13571363.

13. Brody, E., and J. Abelson. 1985. The "spliceosome": yeast pre-messenger RNA associates with a $40 \mathrm{~S}$ complex in a splicingdependent reaction. Science 228:963-966.

14. Brow, D. A., and C. Guthrie. 1989. RNA processing: splicing a spliceosomal RNA. Nature (London) 337:14-15.

15. Chabot, B., D. L. Black, D. M. LeMaster, and J. A. Steitz. 1985. The $3^{\prime}$ splice site of pre-messenger RNA is recognized by a small nuclear ribonucleoprotein. Science 230:1344-1349.

16. Chang, T.-H., M. W. Clark, A. J. Lustig, M. E. Cusick, and J. Abelson. 1988. RNA11 protein is associated with the yeast spliceosome and is localized in the periphery of the cell nucleus. Mol. Cell. Biol. 8:2379-2393.

17. Cheng, S.-C., and J. Abelson. 1987. Spliceosome assembly in yeast. Genes Dev. 1:1014-1027.

18. Devereax, J., P. Haeberli, and O. Smithies. 1984. A comprehensive set of sequence analysis programs for the VAX. Nucleic Acids Res. 12:387-395.

19. England, T. E., A. G. Bruce, and O. C. Uhlenbeck. 1980. Specific labeling of $3^{\prime}$ termini of RNA with T4 RNA ligase. Methods Enzymol. 65:65-74.

20. Fabrizio, P., and J. Abelson. 1990. Two domains of yeast U6 small nuclear RNA required for both steps of nuclear precursor messenger RNA splicing. Science 250:404-409.

21. Fabrizio, P., and J. Abelson. Unpublished results.

22. Fabrizio, P., D. S. McPheeters, and J. Abelson. 1989. In vitro assembly of yeast U6 snRNP: a functional assay. Genes Dev. 3:2137-2150.

23. Frank, D., B. Patterson, and C. Guthrie. 1992. Synthetic lethal mutations identify interactions between U5 snRNA and four proteins required for the second step of splicing. Mol. Cell. Biol. 12:5197-5205.

24. Frendewey, D., and W. Keller. 1985. Stepwise assembly of a pre-mRNA splicing complex requires U-snRNPs and specific intron sequences. Cell 42:355-367.

25. Grabowski, P. J., and P. A. Sharp. 1986. Affinity chromatography of splicing complexes: U2, U5, and U4 + U6 small nuclear ribonucleoprotein particles in the spliceosome. Science 233: 1294-1299.

26. Green, M. R. 1991. Biochemical mechanisms of constitutive and regulated pre-mRNA splicing. Annu. Rev. Cell Biol. 7:559-599.

27. Guthrie, C. 1991. Messenger RNA splicing in yeast: clues to why the spliceosome is a ribonucleoprotein. Science 253:157163.

28. Harlow, E., and D. Lane. 1988. Antibodies: a laboratory manual. Cold Spring Harbor Laboratory Press, Cold Spring Harbor, N.Y.

29. Hashimoto, C., and J. A. Steitz. 1984. U4 and U6 RNAs coexist in a single small nuclear ribonucleoprotein particle. Nucleic Acids Res. 9:3283-3293.

30. Herman, P. K., and S. D. Emr. 1990. Characterization of
VPS34, a gene required for vacuolar protein sorting and vacuole segregation in Saccharomyces cerevisiae. Mol. Cell. Biol. 10: 6742-6754.

31. Hill, J., K. A. Ian, G. Donald, and D. E. Grifiths. 1991. DMSO-enhanced whole cell yeast transformation. Nucleic Acids Res. 19:5791.

32. Hinterberger, M., I. Pettersson, and J. A. Steitz. 1983. Isolation of small nuclear ribonucleoproteins containing $\mathrm{U} 1, \mathrm{U} 2, \mathrm{U} 4, \mathrm{U} 5$, and U6 RNAs. J. Biol. Chem. 258:2604-2613.

33. Horowitz, D. S., and J. Abelson. 1993. Stages in the second reaction of pre-mRNA splicing: the final step is ATP independent. Genes Dev. 7:320-329.

34. Ito, H., Y. Fukuda, K. Murata, and A. Kimura. 1983. Transformation of intact yeast cells treated with alkali cations. J. Bacteriol. 153:163-168.

35. Jackson, S. P., M. Lossky, and J. D. Beggs. 1988. Cloning of the RNA8 gene of Saccharomyces cerevisiae, detection of the RNA8 protein, and demonstration that it is essential for nuclear pre-mRNA splicing. Mol. Cell. Biol. 8:1067-1075.

36. Jacquier, A. 1990. Self-splicing group II and nuclear pre-mRNA introns: how similar are they? Trends Biochem. Sci. 15:351354.

37. Kalmar, G. B., R. J. Kay, A. Lachance, R. Aebersold, and R. B. Cornell. 1990. Cloning and expression of rat liver CTP:phosphocholine cytidylyltransferase: an amphipathic protein that controls phosphatidylcholine synthesis. Proc. Natl. Acad. Sci. USA 87:6029-6033.

38. Kinlaw, C. S., B. L. Robberson, and S. M. Berget. 1983. Fractionation and characterization of human small nuclear ribonucleoproteins containing U1 and U2 RNAs. J. Biol. Chem. 258:7181-7189.

39. Konarska, M. M., and P. A. Sharp. 1987. Interactions between small nuclear ribonucleoprotein particles in formation of spliceosomes. Cell 49:763-774.

40. Krinke, L., and J. Abelson. Unpublished results.

41. Lamm, G. M., G. J. Blencowe, B. S. Sproat, A. M. Iribarren, U. Ryder, and A. I. Lamond. 1991. Antisense probes containing 2-aminoadenosine allow efficient depletion of U5 snRNP from HeLa splicing extracts. Nucleic Acids Res. 19:3193-3197.

42. Lin, R.-J., A. J. Newman, S.-C. Cheng, and J. Abelson. 1985. Yeast mRNA splicing in vitro. J. Biol. Chem. 260:14780-14792.

43. Lossky, M., G. J. Anderson, S. P. Jackson, and J. Beggs. 1987. Identification of a yeast snRNP protein and detection of snRNPsnRNP interactions. Cell 51:1019-1026.

44. Lührmann, R., B. Kastner, and M. Bach. 1990. Structure of spliceosomal snRNPs and their role in pre-mRNA splicing. Biochim. Biophys. Acta 1087:265-292.

45. Lund, E., and J. E. Dahlberg. 1992. Cyclic 2', 3'-phosphates and nontemplated nucleotides at the $3^{\prime}$ end of spliceosomal U6 small nuclear RNA's. Science 255:327-330.

46. Lustig, A. J., R.-J. Lin, and J. Abelson. 1986. The yeast RNA gene products are essential for mRNA splicing in vitro. Cell 47:953-963.

47. Nagai, K., and H. C. Thøgersen. 1987. Synthesis and sequencespecific proteolysis of hybrid proteins produced in Escherichia coli. Methods Enzymol. 153:461-481.

48. Newman, A., and C. Norman. 1991. Mutations in yeast U5 snRNA alter the specificity of $5^{\prime}$ splice-site cleavage. Cell 65:115-123.

49. Newman, A. J., and C. Norman. 1992. U5 snRNA interacts with exon sequences at $5^{\prime}$ and $3^{\prime}$ splice sites. Cell 68:743-754.

50. Patterson, B., and C. Guthrie. 1987. An essential yeast snRNA with a U5-like domain is required for splicing in vivo. Cell 49:613-624.

51. Pearson, W. R., and D. J. Lipman. 1988. Improved tools for biological sequence comparison. Proc. Natl. Acad. Sci. USA 85:2444-2448.

52. Petersen-Bjørn, S., A. Soltyk, J. D. Beggs, and J. D. Friesen. 1989. PRP4 (RNA4) from Saccharomyces cerevisiae: its gene product is associated with the U4/U6 small nuclear ribonucleoprotein particle. Mol. Cell. Biol. 9:3698-3709.

53. Pikielny, C. W., B. C. Rymond, and M. Rosbash. 1986. Electrophoresis of ribonucleoproteins reveals an ordered assembly 
pathway of yeast splicing complexes. Nature (London) 324:341345.

54. Pinto, A. L., and J. A. Steitz. 1989. The mammalian analogue of the yeast PRP8 splicing protein is present in the U4/5/6 small ribonucleoprotein particle and the spliceosome. Proc. Natl. Acad. Sci. USA 86:8742-8746.

55. Robinson, J. S., T. R. Graham, and S. D. Emr. 1991. A putative zinc finger protein, Saccharomyces cerevisiae Vps18p, affects late Golgi functions required for vacuolar protein sorting and efficient $\alpha$-factor prohormone maturation. Mol. Cell. Biol. 12: 5813-5824.

56. Rosbash, M., P. K. Harris, J. L. Woolford, and J. L. Teem. 1981. The effect of temperature-sensitive rna mutants on the transcription products from cloned ribosomal genes of yeast. Cell 24:679-686.

57. Rosbash, M., and B. Séraphin. 1991. Who's on first? The U1 snRNP-5' splice site interaction and splicing. Trends Biochem. Sci. 16:187-190.

58. Rothstein, R. J. 1983. One-step gene disruption in yeast. Methods Enzymol. 101:202-211.

59. Ruby, S. W., and J. Abelson. 1991. pre-mRNA splicing in yeast. Trends Genet. 7:79-85.

60. Schmid, S. R., and P. Linder. 1992. D-E-A-D protein family of putative RNA helicases. Mol. Microbiol. 6:283-292.

61. Séraphin, B., N. Abovich, and M. Rosbash. 1991. Genetic depletion indicates a late role for U5 snRNP during in vitro spliceosome assembly. Nucleic Acids Res. 19:3857-3860.

62. Shannon, K. W., and C. Guthrie. 1991. Suppressors of a U4 snRNA mutation define a novel U6 snRNP protein with RNAbinding motifs. Genes Dev. 5:773-785.

63. Sherman, F., G. R. Fink, and J. B. Hicks. 1986. Methods in yeast genetics. Cold Spring Harbor Laboratory Press, Cold Spring Harbor, N.Y.

64. Struhl, K. 1985. Nucleotide sequence and transcriptional mapping of the yeast pet56-his3-ded1 gene region. Nucleic Acids Res. 13:8587-8601.

65. Studier, F. W., A. H. Rosenberg, J. J. Dunn, and J. W. Dubendorff. 1990. Use of T7 RNA polymerase to direct expression of cloned genes. Methods Enzymol. 185:60-89.

66. Sugino, A., and N. R. Cozzarelli. 1980. The intrinsic ATPase of
DNA gyrase. J. Biol. Chem. 255:6299-6306.

67. Tani, T., and Y. Ohshima. 1991. mRNA-type introns in U6 small nuclear RNA genes: implications for the catalysis in pre-mRNA splicing. Genes Dev. 5:1022-1031.

68. Tsukagoshi, Y., J.-I. Hikawa, and S. Yamashita. 1987. Molecular cloning and characterization of the gene encoding cholinephosphate cytidylyltransferase in Saccharomyces cerevisiae. Eur. J. Biochem. 169:477-486.

69. Utans, U., S.-E. Behrens, R. Lührmann, R. Kole, and A. Krämer. 1992. A splicing factor that is inactivated during in vivo heat shock is functionally equivalent to the [U4/U6.U5] triple snRNP-specific proteins. Genes Dev. 6:631-641.

70. Vijayraghavan, U., and J. Abelson. 1990. PRP18, a protein required for the second reaction in pre-mRNA splicing. Mol. Cell. Biol. 10:324-332.

71. Vijayraghavan, U., M. Company, and J. Abelson. 1989. Isolation and characterization of pre-mRNA splicing mutants of Saccharomyces cerevisiae. Genes Dev. 3:1206-1216.

72. Whittaker, E., and J. D. Beggs. 1990. The yeast PRP8 protein interacts directly with pre-mRNA. Nucleic Acids Res. 19:54835489.

73. Winkelmann, G., M. Bach, and R. Lührmann. 1989. Evidence from complementation assays in vitro that U5 snRNP is required for both steps of mRNA splicing. EMBO J. 8:3105-3112.

74. Wise, J. A., D. Tollervey, D. Maloney, H. Swerdlow, E. J. Dunn, and C. Guthrie. 1983. Yeast contains small nuclear RNAs encoded by single copy genes. Cell 35:743-751.

75. Xu, Y., S. Peterson-Bjørn, and J. D. Friesen. 1990. The PRP4 (RNA4) protein of Saccharomyces cerevisiae is associated with the $5^{\prime}$ portion of the U4 small nuclear RNA. Mol. Cell. Biol. 10:1217-1225.

76. Yean, S.-L., and R.-J. Lin. 1991. U4 small nuclear RNA dissociates from a yeast spliceosome and does not participate in the subsequent splicing reaction. Mol. Cell. Biol. 11:5571-5577.

77. Yoshida, Y., T. Sato, T. Hashimoto, N. Ichikawa, S. Nakai, H. Yoshikawa, F. Imamoto, and K. Tagawa. 1990. Isolation of a gene for a regulatory $15-\mathrm{kDa}$ subunit of mitochondrial $\mathrm{F} 1$ F0-ATPase and construction of mutant yeast lacking the protein. Eur. J. Biochem. 192:49-53. 